Editorial

\title{
Steering in Governance: Evolutionary Perspectives
}

\author{
Raoul Beunen ${ }^{1, *}$ and Kristof Van Assche ${ }^{2}$ \\ ${ }^{1}$ Faculty of Science, Open University, The Netherlands; E-Mail: raoul.beunen@ou.nl \\ 2 Department of Earth and Atmospheric Sciences, University of Alberta, Canada; E-Mail: vanassch@ualberta.ca \\ * Corresponding author
}

Submitted: 7 May 2021 | Published: 25 June 2021

\begin{abstract}
Steering has negative connotations nowadays in many discussions on governance, policy, politics and planning. The associations with the modernist state project linger on. At the same time, a rethinking of what is possible by means of policy and planning, what is possible through governance, which forms of change and which pursuits of common goods still make sense, in an era of cynicism about steering yet also high steering expectations, seems eminently useful. Between laissez faire and blue-print planning are many paths which can be walked. In this thematic issue, we highlight the value of evolutionary understandings of governance and of governance in society, in order to grasp which self-transformations of governance systems are more likely than others and which governance tools and ideas stand a better chance than others in a particular context. We pay particular attention to Evolutionary Governance Theory (EGT) as a perspective on governance which delineates steering options as stemming from a set of co-evolutions in governance. Understanding steering options requires, for EGT, path mapping of unique governance paths, as well as context mapping, the external contexts relevant for the mode of reproduction of the governance system in case. A rethinking of steering in governance, through the lens of EGT, can shed a light on governance for innovation, sustainability transitions, new forms of participation and self-organization. For EGT, co-evolutions and dependencies, not only limit but also shape possibilities of steering, per path and per domain of governance and policy.
\end{abstract}

\section{Keywords}

Evolutionary Governance Theory; governance; planning; policy change; steering

\section{Issue}

This editorial is part of the issue "Steering in Governance: Evolutionary Perspectives" edited by Kristof Van Assche (University of Alberta, Canada / University of Bonn, Germany) and Raoul Beunen (Open University, The Netherlands).

(C) 2021 by the authors; licensee Cogitatio (Lisbon, Portugal). This editorial is licensed under a Creative Commons Attribution 4.0 International License (CC BY).

\section{Introduction}

This thematic issue on steering in governance brings together a diversity of contributions that explore, each in their own way, how an evolutionary understanding offers new insight about steering in governance. The shift from government to governance has inspired an ever-growing diversity of theoretical reflections on the phenomenon of governance. Both in academia and policy practices, many voices have questioned the steering powers of governments as well as the legitimacy of states' steering ambitions (Bell \& Hindmoor, 2009; Pierre \& Peters, 2000; Rhodes, 1996; Stoker, 1998). In conjunction, the scientific reflections on policy, public admin- istration and steering have shifted from what is often labeled as traditional or hierarchical forms of policy making in which governments play pivotal roles, towards a myriad of alternative forms of governance that for example emphasize networks, economic instruments, and the role of private actors (Marais et al., 2021; Niedziałkowski \& Putkowska-Smoter, 2021; Umbach \& Tkalec, 2021). New concepts were developed to label and describe the processes and mechanisms through which societies aim to direct and steer, such as orchestrating, learning, adaptation, meta-governance, or network governance.

Discussions and reflections on steering in governance often revolve on the quest for control. This quest reflects an ongoing search for policy approaches, instruments 
and strategies through which actors, subjects and the future can be directed into a desired state and an ongoing adaptation of policies and strategies to changing circumstances (Van Assche et al., 2020). Within such endeavor one can build on more recent literatures about adaptive governance and institutional change, but also on older lineages of literature that provide insights in the ongoing dynamics of society and the structures through which societies organize and govern themselves, such as social systems theory, actor-network theory, and poststructuralist ideas about the interplay between knowledge and power, between ways of understanding and ways of organizing. Combining and integrating these different theories and their key concepts, one can create an evolutionary perspective on governance that allows for more refined analyses of steering.

\section{An Evolutionary Perspective}

Governance broadly concerns the coordination of collectively binding decisions in a particular context (cf. Pierre, 2000; Van Assche et al., 2014). These contexts can be small groups, organizations, states or even the international domain. Governance can take many different forms. Actors, networks, and institutions are all part of governance and can be coupled in different ways. Governance is always multi-actor and often multi-level. All these aspects can be studied through specific theories, but aspects cannot be on a par with the broader governance phenomenon of which they are part. And while studying these aspects enables a valuable translation into an understanding of specific ways of organizing governance, e.g., through networks or markets, such courses of action evolve within a broader web of processes and mechanisms, which may yield very different effects than what was initially intended. Governance, in other words, is a matter of systems which deserve to be studied as a whole, because, as systems, their emerging logic creates its own effects (Hartley \& Howlett, 2021; Mölders, 2021; von Bertalanffy, 1968). Governance understood as a broader evolutionary phenomenon reveals, also empirically, a multiplicity of perspectives and prescriptions and hence their development and use should be part of a theory of governance (cf. Mielke \& Cermeño, 2021; Voß \& Freeman, 2016). One can speak of a necessary secondorder observation of evolving recipes for good governance, under changing names, rather than a quest for a new recipe.

Governance processes are subject to varying dynamics, meaning that their constitutive elements and structures rely on a diverse host of temporal frameworks and related action repertoires (Gross, 2010). Governance configurations may therefore appear as stable for a while, but even stabilization requires ongoing processes through which elements and structures are constantly constructed and reconstructed (Beunen et al., 2017; Mahoney \& Thelen, 2010). Here one can think of the constant work to reproduce discourses or the need for insti- tutional maintenance (Lawrence et al., 2009). Without ongoing reproduction, discourses would disappear and institutions would become meaningless. Leaning on Machiavelli, one can invoke as illustration the idea of 'democracy': Each example of democracy is de facto a different organization of politics, embedded in a different organization of society, and it takes both institutional design and maintenance, continuous work, to prevent it from backsliding into authoritarian or other non-democratic forms.

Understanding governance as a constant coevolution of different elements and structures has implications for steering. It implies that steering attempts are produced and introduced in an ever-changing context. As such, the success of steering depends on both the fit and adaptive capacity within a given context. First, concerning the fit, a good understanding of the context and dependencies that shape its further evolution is important when developing forms of steering (Alves Rolo et al., 2021; Marais et al., 2021; Van Assche et al., 2021). Second, the success of steering depends on the constant adaptation of steering strategies to changing circumstances (see for example Marais et al., 2021; Mielke \& Cermeño, 2021; Niedziałkowski \& Putkowska-Smoter, 2021; Umbach \& Tkalec, 2021). Steering is a continuous effort that does not stop once a policy is formally introduced. Analyzing what works, responding to shifting strategy patterns by actors involved, and adapting to new circumstances are all part of the steering repertoire. It requires identifying the effects of steering and distinguishing these from the effects caused by other factors (cf. Hartley \& Howlett, 2021). Some effects might go unnoticed, some may only be observed by certain actors or in specific discourses, while other effects might just be observed, but not contribute to steering efforts (Mölders, 2021). Conversely, it is possible that the effects caused by other factors are considered to be successes or failures from steering. Alvesson and Kärreman (2016) provide a striking analysis of over-reliance on success stories in management, and over-attribution of success to steering (by managers). Hence linking forms of steering, strategies and effects to each other is a matter of observation (cf. Luhmann, 2018). Actors in governance need to make decisions based on a specific understanding of the world and a future that is largely unknown. Given the inherent limits to observation and anticipation, a full overview of the possible range of consequences of decision-making is in fact unattainable.

\section{Consequences for Governance}

The different contributions show that steering works better if there is a thorough understanding of the evolutionary path of governance and the different dependencies that structure any further evolutions (Marais et al., 2021; Mielke \& Cermeño, 2021; Niedziałkowski \& Putkowska-Smoter, 2021; Van Assche et al., 2021). Such understanding makes it easier to predict the possible 
chain of changes and adaptions that might occur as a consequence of steering attempts. If people in a particular place tend to follow rules made by the government, it is more likely that they will act according to new rules, compared to places or cultures with a tendency to ignore or circumvent rules made by the government.

An important aspect of the evolutionary path concerns the relation between the actor that aims to steer and the object of steering (Hartley \& Howlett, 2021; Mölders, 2021). A long list of questions quickly emerges, many of which are addressed by the contributors to this thematic issue: Is the object of steering a product of the actor or of the interplay between actors in governance? Is it a pre-existing, or reinterpreted object? Are other actors convinced of its existence and importance? Did a new object 'impose' itself from the environment, triggering a response in governance? Which cognitive and organizational resources does the actor have to grasp the object, its susceptibility to steering, and to translate these insights into steering strategies in governance and through governance?

Steering often works because people believe it to be working and hence act accordingly. Once that belief in steering gets eroded or even lost, it becomes much more difficult to steer and to direct things on a certain path. The loss of belief in the modernist ideals of the welfare state was partly driven by overly high expectations that simply could not be met. This created an environment in which failures and problems gained more attention than successes, in which a loss of confidence in the state and its institutions were increasingly emphasized, and in which alternative models, often focusing on a smaller state, market mechanisms, and deregulation were increasingly promoted. Such alternative perspectives gradually altered the governance system whereby new ideals and perspectives were translate into new forms of organizing, new institutions, new actors and so on. Within those evolving and further diverging governance systems it became harder and harder to restore a belief in steering by and through governments.

Things become more unpredictable and less susceptible to control because of the involvement of more actors and institutions, more perspectives, and because it is difficult in decentralized systems to: a) coordinate governance strategy and steer, b) centralize expert and political observations of the issue at hand, and c) match cognitive and organizational resources in smaller domains of governance. In other words: What might be gained in legitimacy, through de-centralization, participation, localism, can easily be lost because problems become invisible, poorly understood and because actors intent on steering do not have the adequate tools to do so.

One of such problems is that of adaptation. Several contributors to this issue enter this terrain and one observation is that there are likely to be trade-offs between more effective forms of steering and possibilities for adaptation (cf. Alves Rolo et al., 2021; Niedziałkowski \& Putkowska-Smoter, 2021; Umbach \& Tkalec, 2021;
Van Assche et al., 2021). As with centralization and decentralization, steering and adaptation are less incompatible than it looks, and this partial compatibility is a result of the diversity of forms both steering and adaptation can take, and it is related to the diverse effects of each form of steering and each type of adaptation. Indeed, 'adaptation,' is not one thing, not one activity and one mechanism in governance, and adaptation to one thing implies ignoring something else, while some forms of adaptation require long-term perspectives, strong steering, and central coordination (Hartley \& Howlett, 2021; Mielke \& Cermeño, 2021; Umbach \& Tkalec, 2021).

We can conclude this introduction by emphasizing that different steering options create different effects in different contexts and at different moments in time. Furthermore, the effects of steering change because of the effects of previous steering. Steering can change the context in which the next steering attempt, or simply the next step in the same plan, will land. Our authors demonstrate that the contexts can be cultural, economic, institutional, and, last but not least, material. If changes are observed, actors might again adapt their strategies and actions, for example to enhance or alter the effects of steering.

\section{Conflict of Interests}

The authors declare no conflict of interests.

\section{References}

Alves Rolo, R., Van Assche, K., \& Duineveld, M. (2021). Strategy and steering in governance: The changing fates of the Argentine Planning Council. Politics and Governance, 9(2), 415-427.

Alvesson, M., \& Kärreman, D. (2016). Intellectual failure and ideological success in organization studies: The case of transformational leadership. Journal of Management Inquiry, 25(2), 139-152.

Bell, S., \& Hindmoor, A. (2009). Rethinking governance: The centrality of the state in modern society. Cambridge University Press.

Beunen, R., Patterson, J., \& Van Assche, K. (2017). Governing for resilience: The role of institutional work. Current Opinion in Environmental Sustainability, 28, 10-16.

Gross, M. (2010). Ignorance and surprise: Science, society, and ecological design. MIT Press.

Hartley, K., \& Howlett, M. (2021). Policy assemblages and policy resilience: Lessons for non-design from evolutionary governance theory. Politics and Governance, 9(2), 451-459.

Lawrence, T. B., Suddaby, R., \& Leca, B. (2009). Institutional work: Actors and agency in institutional studies of organizations. Cambridge University Press.

Luhmann, N. (2018). Organization and decision. Cambridge University Press.

Mahoney, J., \& Thelen, K. (Eds.). (2010). Explaining insti- 
tutional change: Ambiguity, agency, and power. Cambridge University Press.

Marais, L., Nel, V., Rani, K., van Rooyen, D., Sesele, K., van der Watt, P., \& du Plessis, L. (2021). Economic transitions in South Africa's secondary cities: Governing mine closures. Politics and Governance, 9(2), 381-392.

Mielke, K., \& Cermeño, H. (2021). Mitigating pro-poor housing failures: Access theory and the politics of urban governance. Politics and Governance, 9(2), 439-450.

Mölders, M. (2021). Irritation design: Updating steering theory in the age of governance. Politics and Governance, 9(2), 393-402.

Niedziałkowski, K., \& Putkowska-Smoter, R. (2021). What is the role of the government in wildlife policy? Evolutionary governance perspective. Politics and Governance, 9(2), 428-438.

Pierre, J. (2000). Debating governance, authority, steering, and democracy. Oxford University Press.

Pierre, J., \& Peters, B. G. (2000). Governance, politics, and the state. Macmillan.

Rhodes, R. A. W. (1996). The new governance: Governing without government. Political studies, 44(4),
652-667.

Stoker, G. (1998). Governance as theory: Five propositions. International Social Science Journal, 50(155), 17-28.

Umbach, G., \& Tkalec, I. (2021). Social investment policies in the EU: Actively concrete or passively abstract? Politics and Governance, 9(2), 403-414.

Van Assche, K., Beunen, R., \& Duineveld, M. (2014). Evolutionary governance theory: An introduction. Springer.

Van Assche, K., Beunen, R., Gruezmacher, M., \& Duineveld, M. (2020). Rethinking strategy in environmental governance. Journal of Environmental Policy \& Planning, 22(5), 695-708.

Van Assche, K., Duineveld, M., Gruezmacher, M., \& Beunen, R. (2021). Steering as path creation: Leadership and the art of managing dependencies and reality effects. Politics and Governance, 9(2), 369-380.

von Bertalanffy, L. (1968). General system theory. George Braziller.

Voß, J.-P., \& Freeman, R. (2016). Knowing governance: The epistemic construction of political order. Springer.

\section{About the Authors}

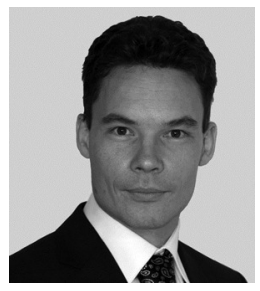

Raoul Beunen is Associate Professor of Environmental Governance at the Open University, The Netherlands. His research explores the potentials and limitations of environmental policy and planning in the perspective of adaptive governance and sustainability. It focuses on innovation and evolution in governance, paying attention to the dynamics of policy implementation and integration, multi-level governance, stakeholder involvement, and the performance of institutional structures.

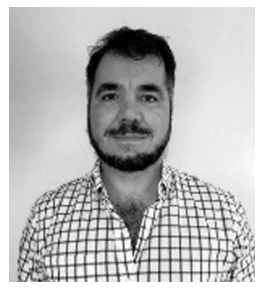

Kristof Van Assche is currently Full Professor (since 2016) in planning, governance and development at the University of Alberta and also affiliated with Bonn University, Center for Development Research (ZEF) as Senior Fellow and with Memorial University, Newfoundland, Harris Centre for Regional Policy, as Research Fellow. Before coming to Alberta (in 2014) he worked at Bonn University (ZEF) as Senior Researcher, Minnesota State University (St Cloud), as Associate Professor, and Wageningen University, as Assistant Professor. He is interested in evolution and innovation in governance, with focus areas in spatial planning and design, development and environmental policy. He has worked in various countries, often combining fieldwork with theoretical reflection: systems theories, interpretive policy analysis, institutional economics, post-structuralism and others. Together with some colleagues he has developed Evolutionary Governance Theory (EGT), which aims to discern realistic modes of transition and reform, between social engineering and laissez faire. 